\title{
Research in advance for FMD Novel Vaccines
}

\author{
Liang Zhang ${ }^{\dagger}$, Jie Zhang ${ }^{\dagger}$, Hao-tai Chen, Jian-hua Zhou, Li-na ma, Yao-zhong Ding and Yong-sheng Liu*
}

\begin{abstract}
Foot-and-Mouth Disease (FMD), as a major global animal disease, affects millions of animals worldwide and remains the main sanitary barrier to the international and national trade of animals and animal products. Inactivated vaccination is the most effective measure for prevention of FMD at present, but fail to induce longterm protection and content new requires for production of FMD vaccines. As a number of Researchers hope to obtain satisfactory novel vaccines by new bio-technology, novel vaccines have been studied for more than thirty years. Here reviews the latest research progress of new vaccines, summarizes some importance and raises several suggestions for the future of FMD vaccine.
\end{abstract}

\section{Introduction}

Foot-and-mouth disease (FMD) is a severe, highly contagious and economically devastating viral disease worldwide (Table 1), which affects animals with cloven hoofed animals, such as cattle, pigs, deer, goats and sheep. It has been reported many outbreaks around the world since FMD firstly broke out in America in 1870. Although not usually fatal, FMD, as a renewed public and political high-profile disease, has aroused the global concerns $[1,2]$. It not only reduces animals' commercial value by decreasing animals' weight and milk output, but is also the most important animal disease limiting commerce of animals and animal products [3]. For those reasons, it is significant to prevent, control and even eradicate FMD.

Vaccines, available since the early 1900s, have been the most instrumental method for prevention and control of FMD. Nowadays, FMD vaccine is produced by growing live velogenic foot-and-mouth disease virus (FMDV) in BHK-21 cell cultures under bio-secure conditions and inactivating it by using a chemical such as binary ethyleneimine. However, the mode of production exist a risk to reveal live FMDV to environment. The risk should be considered by government when FMD has been effectively controlled. Moreover, at the beginning of the 21st century, the protocol for production of inactivated FMD vaccines allows the use of serological

\footnotetext{
* Correspondence: liuyongshengvip8@163.com

+ Contributed equally

State Key Laboratory of Veterinary Etiological Biology, National Foot-and-

Mouth Disease Reference Laboratory, Lanzhou Veterinary Research Institute, Chinese Academy of Agricultural Sciences, Lanzhou, Gansu, China
}

tests that can differentiate infected from vaccinated animals, formulation of vaccines that include multiple serotypes and subtypes and a number of adjuvants [4]. Besides, there are other important shortcomings of current inactivated vaccines, including short shelf life, the need for adequate cold chain of formulated vaccines, and difficulties of certain serotypes and subtypes to grow well in cell culture for vaccine production [5]. In addition, a risk from epidemic areas still exists in countries and areas having been free of FMDV. In order to address these problems, new vaccines are necessary and urgent to develop into satisfied candidates of classical vaccines. According to mechanism, form and source of vaccine, this article reviewed the latest research progress of novel vaccines and some viewpoints for the development of FMD vaccines.

\section{2 subunit vaccine}

Subunit vaccine is a vaccine containing viral antigens made free of viral nucleic acid by chemical extraction or bio-expressing and containing only minimal amounts of non-viral antigens derived from the culture medium. It is less likely to cause adverse reactions than a vaccine containing the whole virion.

With the development of information concerning viral capsid structure, researchers had determined that VP1, one of the FMDV capsid proteins, had a prominent surface exposure in 1970s [6,7]. Based on this information and related researches, a number of strategies were designed to develop subunit vaccines as alternatives to conventional inactivated vaccine. In 1975, Bachrach et al. firstly obtained VP1 isolated from purified viruses 
Table 1 Various serotypes in FMDV distribution areas

\begin{tabular}{|c|c|c|c|c|c|c|c|}
\hline \multirow[t]{2}{*}{ Area } & \multicolumn{7}{|c|}{ Main serotypes in FMDV distribution areas } \\
\hline & Type 0 & Type A & Type C & Type Asia I & SAT-1 & SAT-2 & SAT-3 \\
\hline China & + & + & - & + & - & - & - \\
\hline Southeast Asia & + & + & - & + & - & - & - \\
\hline Africa & + & - & - & - & + & + & + \\
\hline Middle East & + & + & + & + & - & & - \\
\hline United Kingdom & + & - & - & - & - & - & - \\
\hline South America & + & + & + & - & - & - & - \\
\hline
\end{tabular}

"+" means positive, and "-" means negative.

inducing a neutralizing antibody response in swine [8]. In 1981, Kupper cloned the VP1 gene, transferred it into E.coli in the form of recombinant plasmid and harvested the VP1 [9]. Results indicated that VP1 produced in E. coli could protect both swine and cattle from virus challenge [10]. Wang JH, et al. refolded the VP1 with the assistant of SDS and obtained purified VP1 and induced neutralizing antibody responses to every refolding VP1. There was a protective immune response against FMDV challenge in guinea pigs vaccinated with recombinant P1 polyprotein expressed in Pichia pastoris [11]. Shi et al. verified fusion protein of bovine IFNrand FMDV VP1 antigen expressed in P. pastoris could induce an immune response to FMDV antigens [12].

To study FMDV structural proteins and non-structure proteins (NSP), researchers screened several epitopes of VP1. Luis et al. found that TrpE fusion proteins containing portions of the $\mathrm{C}$-terminal region of FMDV VP1 can induce a neutralizing antibody response and certain protection in animal test [13]. Subsequently, Yang and Zhuang separately tested the immune effect of fusion proteins including $\mathrm{T}$ cell and $\mathrm{B}$ cell epitopes. The results indicated that fusion proteins could cause humoral and cellular immune response [14,15].

Empty viral capsids are virus particles lacking nucleic acid which are naturally produced in infected cells and are as immunogenic as virions [7]. In 1979, Rweyemamu confirmed stability and immunogenicity of empty particles of FMDV. Subsequent studies reviewed in vitro expresstion of $\mathrm{P} 1-2 \mathrm{~A}$ and $3 \mathrm{C}$ in cells reformed $76 \mathrm{~s}$ virus-like particles [16]. And Li et al. screened MDBK cells stably co-expressing the capsid precursor protein P1-2A gene and the protease 3C gene of FMDV [17]. The immune effective of virus-like particles is similar to whole FMDV.

Recently new subunit vaccines for FMDV were frequently reported, however, there were no subunit vaccines revealing advanced effective compared with traditional inactivated vaccines. In spite of it, subunit vaccines are still widely regarded as optimal candidates instead of classical inactivated vaccines for advantages, such as high security and the use of serological tests that can differentiate infected from vaccinated animals $[4,18]$. This ideal can be most likely achieved by the development of empty capsid vaccines in future. Utilizing the baculovirus-silkworm expression system, $\mathrm{Li}$ et al. developed recombinant virus vaccine, the immunological assays of guinea pigs demonstrated that this vaccine showed good immunogenicity and long immune persistence.

During the analysis and test of them, some subunit vaccines induced limited protection against virus. According to the characterization of various target protein, it is necessary for subunit vaccines to select an appropriate expression system, such as Bacillus subtilis [19], Cyanobacteria [20], Filamentous fungus [21], Escherichia coli [9], Pichia pastoris [22], Baculovirus [23], Mammalian cell and so on. The last four expression systems of them have been utilized to the development of FMD vaccines. As FMDV is further detailed and expression systems are optimized and improved, the development of subunit vaccines will be promoted.

\section{3 live vector vaccine}

A live vector vaccine is a vaccine that uses a chemically weakened virus to transport pieces of the virus to stimulate an immune response. Adenovirus [24] and poxvirus are widely utilized to efficiently express heterologous genes.

The structure and function of Adenovirus genome has been studied thoroughly. Searchers exploited replication-defective adenovirus serotype 5 (Ad5) as live vector carrying $5 \mathrm{~kb} \sim 8 \mathrm{~kb}$ DNA fragment. Juilliard et al. verified that a single immunization with a replication-defective adenovirus recombinant vector induces long-lasting humoral and cellular immune responses specific to the transgenic product $[25,26]$. Sanz-Parra cloned FMDV P1 gene into Ad5 genome. The animal test displayed that recombinant viruses induced cellular but not humoral antiviral immunity and partial protection in pigs [27]. Mayr developed replication-defective Ad5 containing the capsid and $3 \mathrm{C}$ protease coding regions of foot-andmouth disease virus as a vaccine candidate [28]. The replication-defective Ad5, encoding the FMDV capsid 
coding region and an inactive form of the $3 \mathrm{C}$ proteinase, induced generated high levels of FMDV-neutralizing antibodies 4 weeks later resulting in complete protection of five of the six swine and limited disease in the remaining animal [28]. Early protection against homologous challenge was provided to swine inoculated replication-defective Ad5 expressing capsid proteins of FMDV strain A24 [29]. Correlational researches adenovirus-vectored FMDV vaccine also aroused a rapid protection of cattle from direct challenge with FMDV [30]. Recently studies indicated that there was effective protection of guinea pigs and swine by a recombinant adenovirus expressing $\mathrm{O}$ serotype of foot-and-mouth disease virus whole capsid and 3C protease [31].

Some researchers had an attempt to exploit recombinant vaccinia virus [32] fowlpox virus [33] and pseudorabies virus [34] expressing FMDV structural protein, non-structure protein or both of them, but swine and guinea pigs inoculated with multiple doses were partially protected because of their low level of expression. However, FMD vaccines are required to protect animals from FMDV challenge by a single dose of vaccine in the epidemic period. Although the live vector vaccines appear promising, they are still at earlier stages of testing and development compared to the subunit vaccine candidates.

\section{Nucleic acid vaccines}

Nucleic acid vaccines are genetically engineered DNA to produce an immunological response in injected animals. It has been applied to a number of viral, bacterial and parasitic disease models as well as several tumour models. There are a number of advantages on nucleic acid vaccines over conventional vaccines, such as long-term protection, long shelf life [35] and the ability to induce a wider range of immune response types.

Plasmids have been used for development of DNA vaccines as ideal materials. Plasmids encoding FMDV structural protein and non-structural protein elicited immune responses in mice and swine and protected swine against viral infection [36]. Same other researches reviewed same results [37]. One of the hotspots of new studies of DNA vaccine is focus on the influence of cytokine. Multiple cytokine has been tested as adjuvants of DNA vaccines. There is Table 2 showing the influence of various cytokine on FMDV DNA vaccine [12,38-44]. Based on a large number of tests, some cytokines were identified as effective adjuvants of DNA vaccines. In further researches and development of DNA vaccines, cytokines will play a key role.

\section{Novel attenuated vaccine}

Novel attenuated vaccines are engineered to knock out some regions or oligonucleotides of viruses by biotechnology but not continuously cultured in a non-native susceptible host just as traditional attenuated vaccines. Compared with classical attenuated vaccines, new attenuated methods are stable and low risk of toxicity reversion. There are mainly two strategies exploited to develop novel attenuated vaccines. Based on the researches of FMDV receptor, receptor binding sitedeleted (or replaced) FMDV attenuated vaccine has been explored to protect cattle from FMD $[45,46]$. On the basis of experimental researches into non-required for viral replication, live-attenuated vaccines prepared from a leader proteinase-deficient serotype A12 FMDV [47-49] provided an effective protection to cattle from the challenge of FMDV. These series of experiments demonstrate the potential of a rationally designed liveattenuated FMDV vaccine.

With deeply fundamental researches on the structure and functionality of FMDV proteins, rising mechanisms of virulence and pathogenicity have been reviewed. The leader proteinase of FMDV inhibits the induction of beta interferon mRNA and blocks the host innate immune response [50]. But little is known about other virulence determinants among FMDV genome. As new virulence determinants are identified, the artificial attenuated vaccines will have a further development on

Table 2 The influence of various cytokine on FMDV DNA vaccine

\begin{tabular}{|c|c|}
\hline Cytokine & Effective on FMDV DNA vaccine \\
\hline $\mathrm{IL}-1 / \mathrm{IL}-2$ & Advanced the humoral immune response induced by FMD inactivated vaccines. $[38,39]$ \\
\hline IL-6 & $\begin{array}{c}\text { Advanced the cellular immune response induced by FMD DNA vaccines, Promoting the maturation and immune function of dendritic } \\
\text { cells [40] }\end{array}$ \\
\hline$\| \mathrm{L}-9$ & Increased a robust antigen specific cytotoxicity T lymphocyte response [41] \\
\hline IL-15 & Enhanced the cellular and mucosal immune response and the level of IFN-rinduced by FMD DNA vaccines [42] \\
\hline $\mathrm{IL}-18$ & Increased the immunogenicity of DNA vaccines coding P12A and 3C of FMDV [43] \\
\hline CSF & Enhanced immune responses against a plasmid DNA vaccine encoding FMDV empty capid [44] \\
\hline INF- $\alpha / \beta$ & $\begin{array}{c}\text { Advanced the cellular immune response induced by FMD DNA vaccines, Promoted the maturation and immune function of dendritic } \\
\text { cells }\end{array}$ \\
\hline INF- $\gamma$ & Enhanced both humoral and cell-mediated immune responses[12] \\
\hline
\end{tabular}


condition that this evaluation system of the possibility of reversion to virulence is established.

\section{Synthetic peptide vaccine}

Synthetic peptide vaccine is a viral peptide synthesized by chemical approaches, including antigen epitopes. With the development of information concerning FMDV antigen determinants, antigen regions represented the variable G-H loop found on the surface of the FMDV capsid [51,52] and the carboxy-terminal region of VP1 and corresponded to B cell epitopes. In an earlier experiments [53-55], peptide vaccines against a single epitope of FMD just indicated the limited immunogenicity and particle protection. Further researches implied that an effectively protective VP1 peptide vaccine needs the addition of promiscuous $\mathrm{Th}$ sites from a source outside VP1 [56-58] and potent B cell sites for the induction of high affinity neutralising antibodies $[59,60]$. On the basis of the above researches, researchers have designed novel synthetic peptide vaccines with $T$ and $B$ cell sites optimised for both immunogenicity and antigenic cross-reactivities. This peptide immunogen spans the entire G-H loop domain and extensive flanking sequences (129-169), has a unique consensus sequence to confront the hypervariability of serotype $\mathrm{O}$ viruses, and includes a promiscuous artificial Th site [61]. A dendrimeric peptide vaccine was described to protect pigs against challenge with FMDV and induce high titers of FMDV neutralizing antibodies, activated FMDV-specific $\mathrm{T}$ cells and a potent antiFMDV immunoglobulin A response [62]. The research suggested that peptide vaccines representing appropriate advanced structure preferably more possibly induced a fully protective immune response, and rational designs of advanced structure of antigen peptide would provide a new development of peptide vaccines.

\section{Conclusion}

The globalization of commerce is accelerating the spread of FMDV and presents new requirements on the trade of animals and animal productions. But novel vaccines against FMDV are developed slowly, and only few available novel FMD vaccines have been used in practice. New vaccines are still just tested and evaluated in laboratory and clinic, due to limited details on immune mechanism of each of novel vaccines and the basic researches of FMDV. However, a number of results implied that there were observed advantages and disadvantages on novel vaccines arrange the security of production, the security of vaccinated animal, shelf life, duration of immune response, vaccination effectiveness and differentiation of infected animals from vaccinated ones(Table 3).

We should also do some efforts to the development of adjuvants and immunization strategies. Some researchers reported that combination immunization with DNA vaccines and subunit vaccines or synthetic peptide vaccines could induced a high-titer specific antibodies and cellular immunity. This strategy will be a nearest way to make different vaccines complement each other and proceed to the practice of novel vaccines, on the condition that researchers are puzzled to develop a single novel vaccine for controlling FMDV.

\section{Acknowledgements}

This work was supported in parts by grants from National Science \& Technology Key Project (2009ZX08007-006B) and International Science \& Technology Cooperation Program of China (No. 2010DFA32640) and Science and Technology Key Project of Gansu Province (No. 0801NKDA034). This study was also supported by National Natural Science foundation of China (No. 30700597 and No. 31072143).

\section{Authors' contributions}

LZ and JZ contributed equally to the original draft of the manuscript, and approved the final version. HTC and JHZ helped to provide information and suggestion. LNM and YZD contributed to conception and design of the manuscript, and revised the manuscript. YSL is the corresponding author. All authors read and approved the final manuscript.

Competing interests

The authors declare that they have no competing interests.

Received: 22 March 2011 Accepted: 3 June 2011 Published: 3 June 2011

Table 3 Advantages and disadvantages of different novel vaccines

\begin{tabular}{|c|c|c|c|c|c|c|}
\hline Novel vaccines & $\begin{array}{l}\text { security of } \\
\text { production }\end{array}$ & $\begin{array}{l}\text { security of vaccinated } \\
\text { animal }\end{array}$ & $\begin{array}{l}\text { shelf } \\
\text { life }\end{array}$ & $\begin{array}{l}\text { duration of } \\
\text { immune response }\end{array}$ & $\begin{array}{l}\text { vaccination } \\
\text { effectiveness }\end{array}$ & $\begin{array}{l}\text { Differentiation of infected animals } \\
\text { from vaccinated ones }\end{array}$ \\
\hline Subunit vaccine & Yes & Yes & Normal & Normal & Low & Yes \\
\hline $\begin{array}{l}\text { Live vector } \\
\text { vaccine }\end{array}$ & Yes & Yes & Normal & Long & High & Yes \\
\hline $\begin{array}{l}\text { Nucleic acid } \\
\text { vaccine }\end{array}$ & Yes & $\begin{array}{l}\text { Risk to recombinant to } \\
\text { other genomes }\end{array}$ & Long & Long & Low & Yes \\
\hline $\begin{array}{c}\text { Novel } \\
\text { attenuated } \\
\text { vaccine }\end{array}$ & Yes & $\begin{array}{c}\text { Risk to toxicity reversion } \\
\text { but low }\end{array}$ & Normal & Long & High & Yes \\
\hline $\begin{array}{l}\text { Synthetic } \\
\text { peptide vaccine }\end{array}$ & Yes & Yes & Normal & Short & Low & Yes \\
\hline
\end{tabular}




\section{References}

1. Sumption K, Rweyemamu M, Wint W: Incidence and distribution of footand-mouth disease in Asia, Africa and South America, combining expert opinion, official disease information and livestock populations to assist risk assessment. Transboundary and Emerging Diseases 2008, 55(1):5-13.

2. Gibbs P: The foot-and-mouth disease epidemic of 2001 in the UK: implications for the USA and the "war on terror". Journal of Veterinary Medical Education 2003, 30(Summer 2):121-32.

3. Mort M, Convery I, Baxter J, Bailey C: Psychosocial effects of the 2001 UK foot and mouth disease epidemic in a rural population: qualitative diary based study. BMJ (Clinical Research Ed) 2005, 331(7527):1234.

4. Doel TR: FMD vaccines. Virus Research 2003, 91(1):81-99.

5. Rodriguez LLuis, Grubman JMarvin: Foot and mouth disease virus vaccines. Vaccine 2009, 27:D90-D94.

6. Laporte J: The structure of foot-and-mouth disease virus protein. J Gen Virol 1969, 4(4):631-634.

7. Rowlands DJ, Sangar DV, Brown F: Relationship of the antigenic structure of foot-and-mouth disease virus to the process of infection. J Gen Virol 1971, 13(1):85-93.

8. Bachrach HL, Moore DM, McKercher PD, Polatnick J: Immune and antibody responses to an isolated capsid protein of foot-and-mouth disease virus. Journal of Immunology 1975, 115(6):1636-1641.

9. Küpper Hans, Keller Walter, Kurz Christina, Forss Sonja, Schaller Heinz, Franze Reinhard, Strohmaier Karl, Marquardt Otfried, Zaslavsky GVladimir, Hofschneider Peter Hans: Cloning of cDNA of major antigen of foot-andmouth disease virus and expression in E.coli. Nature 1981, 289:555-559.

10. Kleid DG, Yansura D, Small B, Dowbenko D, Moore DM, Grubman MJ, McKercher PD, Morgan DO, Robertson BH, Bachrach HL: Cloned viral protein vaccine for foot-and-mouth disease: responses in cattle and swine. Science 1981, 214:1125-1129.

11. Balamurugan V, Renji R, Saha SN, Reddy GR, Gopalakrishna S, Suryanarayana WS: Protective immune response against foot-and-mouth disease virus challenge in guinea pigs vaccinated with recombinant $\mathrm{P} 1$ polyprotein expressed in Pichia pastoris. Arch Virol 2005, 19(1):513-516.

12. Shi XJ, Wang B, Zhang C, Wang M: Expressions of bovine IFN-yand footand-mouth disease VP1 antigen in P. pastoris and their effects on mouse immune response to FMD antigens. Vaccine 2006, 24:82-89.

13. Luis DGiavedoni, Gerardo Kaplan, Felipe Marcovecchio, Elisa Piccone Maria, Palma LEduardo: Protection conferred by TrpE fusion proteins containing portions of the $\mathrm{C}$-terminal region of capsid protein VP1 of foot -and -mouth disease virus. Journal of General Virology 1991, 72:967-971.

14. Yang Zhi jun, Lin Yan, Lil Guang jin, Yan Wei yao, Xu Quan xing, You Yong jin, Zheng Zhao xing: Recombinant Vaccine Containing Both B Cell and T Cell Epitopes Induces Guinea Pig in Immune Responses Against Type O Foot-and-Mouth Disease Virus. Journal of Fudan University 2000, 39(5):564-568

15. Juan Zhuang, Xiang-rong Cao, bo Cheng, Zhong Rao, Jie Pan, Quanxing $\mathrm{Xu}$, Yong-jin You: The immune responses of the fusion protein including two copies of T cell and B cell epitopes of Food-and-mouth disease VP1. Chinese Journal of Preventive Veterinary Medicine 2005, 27(6):494-503

16. Rweyemamu MM, Terry G, Pay TW: Stability and immunogenicity of empty particles of foot-and-mouth disease virus. Archives of Virology 1979, 59(1-2):69-79.

17. Li J, L iu Y, Liu X, et al: Screening and stability of Madin-Darby bovine kidney cell strain co-expressing the capsid precursor protein P1-2A gene and the protease $3 \mathrm{C}$ gene of foot-and-mouth disease virus. Acta Microbiologica Sinica 2008, 48(11):1520-1525.

18. Grubman MJ: Development of novel strategies to control foot-andmouth disease: marker vaccines and antivirals. Biologicals 2005, 33:227-234.

19. Sau-Ching Wu, Ruiqiong Ye, Xu-Chu Wu, Shi-Chung Ng, Sui-Lam Wong: Enhanced secretory production of a single-chain antibody fragment from Bacillus subtilis by coproduction of molecular chaperones. Bacterio/ 1998, 180(11):2830-2835

20. Leung WC, Manavathu EK, Zavaagstra J, Surunaraynan K: Development of fungal nd algal cells for expression of foreign genes. Applied Virology Academic Press New York; 1986, 25-30.

21. Tikoo SK, Fitzpatrick DR, Babiuk LA, Zamb TJ: Molecular cloning, sequencing, and expression of functional bovine herpesvirus 1 glycoprotein gIV in transfected bovine cells. J Virol 1990, 64(10):5132-5142.

22. Balamurugan V, Renji R, Saha SN, Reddy GR, Gopalakrishna S, Suryanarayana $\mathrm{W}$ : Protective immune response of the capsid precursor polypeptide (P1) of foot and mouth disease virus type ' $\mathrm{O}$ ' produced in Pichia pastoris. Virus Research 2003, 92(2003):141-149.

23. Zhiyong Li, Yongzhu Yi, Xiangping Yin, Zhifang Zhang, Jixing Liu: Expression of foot-and-mouth disease virus capsid proteins in silkwormbaculovirus expression system and its utilization as a subunit vaccine. PLoS One 2008, 3(5):e2273.

24. Xiang ZQ, Yang Y, Wilson JM, Ertl HC: A replication defective human adenovirus recombinant serves as a highly efficacious vaccine carrier Virology 1996, 219:220-227.

25. Juillard V, Villefroy P, Godfrin D, Pavirani A, Venet A, Guillet JG: Long-term humoral and cellular immunity induced by a single immunization with replication-defective adenovirus recombinant vector. Eur J Immunol 1995, 25:3467-3473.

26. Fooks AR, Jeevarajah D, Lee J, Warnes A, Niewiesk S, ter Meulen $V$ Stephenson JR, Clegg JC: Oral or parenteral administration of replicationdeficient adenoviruses expressing the measles virus haemagglutinin and fusion proteins: protective immune responses in rodents. J Gen Virol 1998, 79:1027-1031.

27. Sanz-Parra A, Jimenez-Clavero MA, GarcÃ-a-Briones MM, Blanco E, Sobrino F, Ley $V$ : Recombinant viruses expressing the foot-and-mouth disease virus capsid precursor polypeptide(P1) induce cellular but not humoral antiviral immunity and partial protection in pigs. Virology 1999, 259:129-134

28. Mayr GA, Chinsangaram J, Grubman MJ: Development of replicationdefective adenovirus serotype 5 containing the capsid and $3 C$ protease coding regions of foot-and-mouth disease virus as a vaccine candidate. Virology 1999, 263(2):496-506.

29. Moraes MP, Mayr GA, Mason PW, Grubman MJ: Early protection against homologous challenge after a single dose of replication-defective human adenovirus type 5 expressing capsid proteins of foot-and-mouth disease virus (FMDV) strain A24. Vaccine 2002, 20(11-12):1631-1639.

30. Pacheco JM, Brum MC, Moraes MP, Golde WT, Grubman MJ: Rapid protection of cattle from direct challenge with foot-and-mouth disease virus (FMDV) by a single inoculation with an adenovirus-vectored FMDV subunit vaccine. Virology 2005, 337(2):205-209.

31. Lu Z, Bao H, Cao Y, Sun P, Guo J, Li P, Bai X, Chen Y, Xie B, Li D, Liu Z, Xie Q: Protection of guinea pigs and swine by a recombinant adenovirus expressing $O$ serotype of foot-and-mouth disease virus whole capsid and 3 C protease. Vaccine 2008, 26:G48-G53.

32. Berinstein A, Tami $C$, Taboga $O$, Smitsaart $E$, Carrillo E: Protective immunity against foot-and-mouth disease virus induced by a recombinant vaccinia virus. Vaccine 2000, 18:2231-2238.

33. Zheng $M$, Jin N, Zhang $H$, Jin M, Lu H, Ma M, Li C, Yin G, Wang R, Liu Q: Construction and immunogenicity of a recombinant fowlpox virus containing the capsid and $3 c$ protease coding regions of foot-andmouth disease virus. J Virol Methods 2006, 136:230-237.

34. Yao Q, Qian P, Huang Q, Cao Y, Chen H: Comparison of immune responses to different foot-and-mouth disease genetically engineered vaccines in guinea pigs. J Virol Methods 2008, 147(1):143-150.

35. Hu Y, Jin H, Du X, Xiao C, Luo D, Wang B, She R: Effects of chronic heat stress on immune responses of the foot-and-mouth disease DNA vaccination. DNA Cell Biol 2007, 26(8):619-26.

36. Wong HT, Cheng SCS, Chan EWC, Sheng ZT, Yan WY, Zheng ZX, Xie Y: Plasmids encoding foot-and-mouth disease virus VP1 epitopes elicited immune responses in mice and swine and protected swine against viral infection. Virology 2000, 278(1):27-35.

37. Benvenisti L, Rogel A, Kuznetzova L, Bujanover S, Becker Y, Stram Y: Gene gun-mediate DNA vaccination against foot-and- mouth disease virus. Vaccine 2001, 19:3885-3895.

38. Shao HJ, Chen L, Su YB: DNA fragment encoding human IL-1beta 163171 peptide enhances the immune responses elicited in mice by DNA vaccine against foot-and-mouth disease. Vet Res Commun 2005, 29(1):35-46.

39. Hong-Ying Zhang, Shu-Han Sun, Ying-Jun Guo, Wei-Jia Zhu, Ke Shi, GenXing Xu, Jian-Jun Wang: Optimization strategy for plasmid DNAs containing multiple-epitopes of foot-and-mouth disease virus by cisexpression with IL-2. Vaccine 2008, 26(6):769-77. 
40. Su B, Wang J, Wang $X$, Jin $H$, Zhao G, Ding Z, Kang $Y$, Wang B: The effects of IL- 6 and TNF-alpha as molecular adjuvants on immune responses to FMDV and maturation of dendritic cells by DNA vaccination. Vaccine 2008, 26(40):5111-22.

41. Qiang Zou, Bing Wu, Xiaodan He, Yizhi Zhang, Youmin Kang, Jin Jin, Hanqian Xu, Hu Liu, Bin Wang: Increasing a robust antigen-specific cytotoxic T lymphocyte response by FMDV DNA vaccination with IL-9 expressing construct. J Biomed Biotechnol 2010, 2010, Article ID 562356.

42. Xiao Wang, Xinyu Zhang, Youming Kang, Huali Jin, Xiaogang Du, Gan Zhao, Yang Yu, Jinyao Li, Baowei Su, Chang Huang, Bin Wang: Interleukin-15 enhance DNA vaccine elicited mucosal and systemic immunity against foot and mouth disease virus. Vaccine 2008, 26(40):5135-44.

43. Ma M, Jin N, Shen G, Zhu G, Liu HJ, Zheng M, Lu H, Huo X, Jin M, Yin G, $\mathrm{Ma} \mathrm{H}$, Li X, Ji Y, Jin K: Immune responses of swine inoculated with a recombinant fowlpox virus co-expressing $\mathrm{P} 12 \mathrm{~A}$ and $3 \mathrm{C}$ of FMDV and swine IL-18. Vet Immunol Immunopathol 2008, 121(1-2):1-7.

44. Li Y, Aggarwal N, Takamatsu HH, Sterling CM, Voyce C, Barnett PV: Enhancing immune responses against a plasmid DNA vaccine encoding FMDV empty capid from serotype O. Vaccine 2006, 24:4602-4606.

45. Rieder E, Baxt B, Lubroth J, Mason PW: Vaccines prepared from chimeras of foot-and-mouth disease virus (FMDV) induce neutralizing antibodies and protective immunity to multiple serotypes of FMDV. J Virol 1994, 68(11):7092-7098.

46. McKenna TS, Lubroth J, Rieder E, Baxt B, Mason PW: Receptor binding sitedeleted foot-and-mouth disease (FMD) virus protects cattle from FMD. J Virol 1995, 69(9):5787-5790.

47. Piccone ME, Rieder E, Mason PW, Grubman MJ: The foot-and-mouth disease virus leader proteinase gene is not required for viral replication. J Virol 1995, 69(9):5376-5382.

48. Chinsangaram J, Mason PW, Grubman MJ: Protection of swine by live and inactivated vaccines prepared from a leader proteinase-deficient serotype A12 foot-and-mouth disease virus. Vaccine 1998, 16(16):1516-1522.

49. Mason PW, Piccone ME, Mckenna TS, Chinsangaram J, Grubman MJ: Evaluation of a live-attenuated foot-and-mouth disease virus as a vaccine candidate. Virology 1997, 227(1):96-102.

50. de Los Santos T, de Avila Botton S, Weiblen R, Grubman MJ: The leader proteinase of foot-and-mouth disease virus inhibits the induction of beta interferon mRNA and blocks the host innate immune response. J Virol 2006, 80(4):1906-14.

51. Pfaff E, Mussgay M, Bohm HO, Schulz GE, Schaller H: Antibodies against a preselected peptide recognise and neutralise foot and mouth disease virus. EMBO J 1982, 17:869-874.

52. Acharya R, Fry E, Stuart D, Fox G, Rowlands D, Brown F: The three dimensional structure of foot-and-mouth disease virus at $2.9 \AA$ resolution. Nature 1989, 337(6209):709-16.

53. Bittle LJames, Houghten ARichard, Hannah Alexander, Shinnick MThomas, Sutcliffe J Gregor, Lerner ARichard, Rowlands JDavid, Fred Brown: Protection against foot-and-mouth disease by immunisation with a chemically synthesised peptide predicted from the viral nucleotide sequence. Nature 1982, 298:30-33.

54. DiMarchi R, Brooke G, Gale C, Cracknell V, Doel T, Mowat N: Protection of cattle against foot-and-mouth disease by a synthetic peptide. Science 1986, 232:639-641.

55. Brown F: New approaches to vaccination against foot-and-mouth disease. Vaccine 1992, 1014:1022-1026.

56. Taboga O, Tami C, Carrillo E, Núñez JI, Rodríguez A, Saíz JC, Blanco E, Valero ML, Roig X, Camarero JA, Andreu D, Mateu MG, Giralt E, Domingo E, Sobrino F, Palma EL: A large-scale evaluation of peptide vaccines against foot-and-mouth disease: lack of solid protection in cattle and isolation of escape mutants. J Virol 1997, 714:2606-2614.

57. García-Briones MM, Russell GC, Oliver RA, Tami C, Taboga O, Carrillo E, Palma EL, Sobrino F, Glass EJ: Association of Bovine DRB3 Alleles with immune response to FMDV peptides and protection against viral challenge. Vaccine 2001, 19:1167-1171.

58. Francis MJ, Hastings GZ, Syred AD, McGinn B, Brown F, Rowlands DJ: Nonresponsiveness to a foot-and-mouth disease virus peptide overcome by addition of foreign helper T cell determinants. Nature 1987, 330:168-170.

59. Meloen RH, Casal Jl, Dalsgaard K, Langeveld JPM: Synthetic peptide vaccines: success at last. Vaccine 1995, 1310:885-886.
60. Steward MW, Stanley CM, DiMarchi R, Mulcahy G, Doel TR: High-affinity antibody induced by immunisation with a synthetic peptide is associated with protection of cattle against foot-and-mouth disease. Immunology 1991, 721:99-103.

61. Wang CY, Chang TY, Walfield AM, Ye J, Shen M, Chen SP, Li MC, Lin YL, Jong $M H$, Yang PC, Chyr N, Kramer E, Brown F: Effective synthetic peptide vaccine for foot-and-mouth disease in swine. Vaccine 2002, 20:2603-2610.

62. Cubillos Carolina, de la Torre GBeatriz, Jakab Annamaria, Clementi Giorgia, Borra's Eva, Ba'rcena Juan, Andreu David, Sobrino Francisco, Blanco Esther: Enhanced Mucosal Immunoglobulin A Response and Solid Protection against Foot-and-Mouth Disease Virus Challenge Induced by a Novel Dendrimeric Peptide. J Virol 2008, 82:7223-7230.

doi:10.1186/1743-422X-8-268

Cite this article as: Zhang et al:: Research in advance for FMD Novel Vaccines. Virology Journal 2011 8:268.

\section{Submit your next manuscript to BioMed Central and take full advantage of:}

- Convenient online submission

- Thorough peer review

- No space constraints or color figure charges

- Immediate publication on acceptance

- Inclusion in PubMed, CAS, Scopus and Google Scholar

- Research which is freely available for redistribution

Submit your manuscript at www.biomedcentral.com/submit
Biomed Central 